\title{
Indian Contract research - economic necessity or sellout?
}

The Indian government is encouraging its laboratories to engage in contract research with Western pharmaceutical companies as a means of boosting finances. The staterun Council of Scientific and Industrial Research (CSIR) has asked around 40 of its laboratories to raise 50 percent of their budget through consultancies and contracts. Last year the CSIR earned $\$ 2.5$ million from this source, a figure set to rise this year. When the US firm Monsanto needed a synthetic gene recently, it turned to the Indian Institute of Science (IIS) in Bangalore. "They gave us the gene sequence and asked us to synthesize it," says IIS biochemist Satyanarayana Rao. Monsanto paid \$10,000 for the job.

But as more fund-starved government institutes hire out their facilities and staff, some researchers are worried by what they see as a disturbing trend. A.V. Rama Rao, who retired as director of Indian Institute of Chemical Technology (IICT) last year, describes the situation as a "sellout" and warns that it might send the wrong signals to companies seeking cheap labor. "Our collaborations should be knowledge-based and as equals." Rama Rao fears that a diversion of government laboratories to meet the goals of foreign companies will be disastrous for Indian research in the long run. However, Ragunath Mashelkar, a secretary in the science ministry and director general of CSIR, claims that national priorities have not been subverted, as only ten percent of the non-budgetary revenue of CSIR comes from foreign firms.

Although the low labor cost does entice foreign companies to do business in India, Ralph Scannel, director of medicinal chemistry at US-based Cytomed, insists that it is not the only reason why his company "made a strategic decision" to work with organizations like the IICT in Hyderabad. "Cytomed's goal was to utilize a highly educated and trained work force which we have found to be very flexible and responsive to our needs," he says, and claims the institute's work in redesigning a drug molecule process for the company "was far superior to what we would have obtained here in the US or in Europe." DuPont Merck's Ervin Lipp agrees: "We have a number of research agreements here in
India spending about one million dollars annually. The institutions and personnel are world class." IICT director K.V. Raghavan says that besides bringing money for the institute, contract research provides an opportunity for his scientists to understand the nature of US drug discovery and development.

Many foreign companies use contract research as a stepping stone for entry into the wider drug market that India offers. Astra of Sweden, which first entered into collaboration with IIS in the eighties, now has a subsidiary R\&D center in Bangalore. Both Monsanto and DuPont Merck have announced plans to set up their own Indian research units in the near future.

But doing research in India is not with-

out drawbacks. Some multinational companies still view cultural barriers as a major bottleneck and express concern over the confidentiality of institutions run primarily with tax-payers' money.

Regardless of the criticism it is attracting, contract pharmaceutical research is expected to grow given the declining government budgetary support for biomedical research. India's R\&D spending dropped from 1.0 precent of GDP in 1991 to 0.81 in 1996. For those wondering why the Indian government has not established a separate contract research facility, the answer is that it has been slow off the mark. A \$40 million National Institute of Biologicals being built near Delhi-with Japanese and US assistance-to carry out contract research in addition to the quality control of biological products will not be ready before 2000 .

K.S. JAYARAMAN New Dehli

\section{New lease on life for aging research}

In the past few weeks, 96 journals from 31 countries have coordinated publication of articles on, and in some cases dedicated entire issues to, various aspects of aging. Last month also saw the announcement of a new peer-reviewed scientific and clinical research journal, the Journal of Anti-aging Medicine.

This broad spotlight on aging-related research and health care of the elderly - traditionally areas that have received scant attention - has been triggered by the startling demographics of aging populations in many countries. As Knight Steele, of the Homecare Institute in New Jersey, writing in JAMA's October 22 Global Theme Issue on Aging, points out, the increasing percentage of populations that are over 65 is a feature not only of Western countries but also of developing nations, making aging an international priority. The United Nations has recently designated 1999 as "The International Year of Older Persons."

It has been calculated that during the next 40 years the proportion of the UK population between 65 and 74 years of age will increase by 40 percent, a trend that has prompted Britain's Biotechnology and Biological Sciences Research Council to designate "the science of ageing" a priority area for the allocation of Ph.D. studentships.

Research into Ageing (RIA), a UK charity that hands out around a half a million pounds $(\$ 800,000)$ in research grants per annum, recently launched an anniversary appeal to raise one million pounds to finance the Queen Mother postdoctoral fellowship program. Future proposed projects include the setting-up of postdoctoral fellowships designed to foster greater collaboration between US and UK investigators working in the aging field. "Aging research is now much more directed towards improving the quality of life than increasing longevity," says RIA's director Elisabeth Mills.

The RIA, in conjunction with SmithKline Beecham, the Medical Research Council (MRC), BUPA and Westminster Healthcare, has sponsored a project called AgeNet to which they have pledged a total of half a million pounds over three years. "AgeNet is designed to stimulate new collaborations in research to meet the needs of increasing numbers of elderly people," says Rob Lang of the MRC. The first in a series of AgeNet workshops was held in London two weeks ago to discuss ways in which new technologies can improve the later years of life.

ORLA SMITH 